\title{
ENSO's impacts on the tropical Indian and Atlantic Oceans via tropical atmospheric processes: observations versus CMIP5 simulations
}

\author{
Shan $\mathrm{He}^{1,2} \cdot$ Jin-Yi Yu² . Song Yang 1,3,4 . Shih-Wei Fang ${ }^{2}$
}

Received: 25 July 2019 / Accepted: 15 April 2020 / Published online: 23 April 2020

(C) The Author(s) 2020

\begin{abstract}
This study compares the impacts of the El Niño-Southern Oscillation (ENSO) on sea surface temperatures (SSTs) in the tropical North Atlantic Ocean and the tropical Indian Ocean during 1958-2004. It is found that the tropical atmospheric processes mediating the ENSO impacts are different between the two oceans for two reasons. First, the ENSO-induced anomalous Walker circulation is more extensive over the Atlantic than over the Indian Ocean. As a result, the atmospheric bridge (AB) mechanism is the major contributor to the differences in ENSO teleconnections between the two oceans. Secondly, SSTs in the tropical North Atlantic are under a greater control of the atmospheric thermal forcing than those in the tropical Indian Ocean. Due to these different controls, the tropospheric temperature (TT) mechanism also contributes to the different ENSO teleconnections. When compared with the observations, the mean of thirty-seven models from the Coupled Model Intercomparison Project Phase 5 overestimates the ENSO-induced SST response in the tropical Indian Ocean but underestimates the response in the tropical North Atlantic. The overestimation is brought about by a westward extension of ENSO SST anomalies in the models, which causes the AB mechanism to produce an overly strong impact on Indian Ocean SSTs. On the other hand, the underestimation is caused by a weaker-than-observed sensitivity in the simulated Atlantic SSTs to the thermal forcing produced by the TT mechanism.
\end{abstract}

Keywords El Niño-Southern Oscillation · CMIP5 models · Atmospheric bridge mechanism · Tropospheric temperature mechanism

\section{Introduction}

The neighboring tropical Atlantic and Indian Oceans are influenced by the El Niño-Southern Oscillation (ENSO) in the tropical Pacific Ocean which produces profound climate impacts worldwide (e.g., Rasmusson and Carpenter 1982;

Jin-Yi Yu

jyyu@uci.edu

Song Yang

yangsong3@mail.sysu.edu.cn

1 School of Atmospheric Sciences, Sun Yat-sen University, Guangzhou, Guangdong, China

2 Department of Earth System Science, University of California at Irvine, Irvine, CA, USA

3 Guangdong Province Key Laboratory for Climate Change and Natural Disaster Studies, Sun Yat-sen University, Guangzhou, Guangdong, China

4 Southern Marine Science and Engineering Guangdong Laboratory (Zhuhai), Zhuhai, Guangdong, China
Kousky et al. 1984; Trenberth et al. 1998; Yu et al. 2012, 2017; Xie et al. 2016). During El Niño (La Niña) events, significant positive (negative) sea surface temperature (SST) anomalies are observed in the tropical Atlantic and Indian Oceans (Enfield and Mayer 1997; Klein et al. 1999; Alexander et al. 2002; Schott et al. 2009). These anomalies typically peak in strength two to four months after ENSO events fully develop (e.g., Klein et al. 1999; Wang et al. 2004). The ENSO-induced Atlantic and Indian Ocean SST variations can not only modulate the climate within the basins (Marengo et al. 2008; Wu et al. 2010) but also exert the feedback influencing ENSO evolution (Yu et al. 2002; Kug and Kang 2006; Ham et al. 2013; Wang et al. 2017).

The atmosphere serves as a key medium for tropical inter-basin teleconnections during ENSO events. Previous studies have identified at least two key tropical atmospheric mechanisms through which ENSO events disturb the atmospheric circulation and thus transmit ENSO's influences to the neighboring tropical oceans (Cai et al. 2019). One is the atmospheric bridge (AB) mechanism 
(Klein et al. 1999; Alexander et al. 2002) and the other is the tropospheric temperature (TT) mechanism (Chiang and Sobel 2002; Su et al. 2003, 2005; Chiang and Lintner 2005). The AB mechanism works by displacing the Walker circulation to induce changes in cloudiness and surface wind speeds. These changes alter surface radiative, sensible, and latent heat fluxes, thus producing SST variations underneath (Ramanathan and Collins 1991; Xie and Philander 1994; Ohba and Ueda 2005; Chowdary and Gnanaseelan 2007; Du et al. 2009; Talley et al. 2011). The TT mechanism involves warming (or cooling) of the overlying troposphere. The anomalous temperatures then excite atmospheric Kelvin and Rossby waves (i.e., the Gill-type response) that rapidly spread the local anomalous warming (cooling) throughout the entire tropical troposphere. Subsequently, the warming (cooling), on its arrival over remote oceans, induces SST variations underneath through surface sensible and latent heat fluxes.

The TT mechanism relies on waves propagating through the tropical troposphere. This mechanism may produce similar impacts on the tropical Atlantic and Indian Oceans. In contrast, the $\mathrm{AB}$ mechanism works by displacing the Pacific Walker circulation and does not necessarily produce similar impacts on the two neighboring tropical oceans (Gill 1980; Lau and Lim 1982). The AB and TT mechanisms may have different contributions to the observed inter-basin teleconnections of ENSO. In this study, we examine the relative contributions of these two mechanisms in the observations. We also examine if contemporary climate models can realistically simulate both mechanisms. If not, we then study the causes of the model deficiencies. Coupled climate models, such as the Coupled Model Intercomparison Project Phase 5 (CMIP5) models, have been frequently used to project future changes in ENSO and its global impacts (Du et al. 2013; Liu et al. 2013, 2014; Chowdary et al. 2014; Capotondi 2015; Tao et al. 2016). How well the models simulate the AB and TT mechanisms greatly influences their ability to project the ENSO impacts.

Apart from the tropical atmospheric mechanisms, extratropical atmospheric processes also play a role in establishing ENSO's impacts on the neighboring oceans. The ENSO events can, for example, induce SST variations in the North Atlantic Ocean via the Pacific-North American pattern propagating through the extratropical atmosphere (Giannini et al. 2000). Additionally, ocean dynamics and coupled ocean-atmosphere processes can also modulate the ENSO impacts produced by the AB and TT mechanisms (Shinoda et al. 2004; Du et al. 2009; Deser et al. 2010; Wu and Yeh 2010). Nevertheless, the tropical atmospheric mechanisms (i.e., the $\mathrm{AB}$ and $\mathrm{TT}$ mechanisms) remain the major processes shaping the responses of neighboring tropical oceans to ENSO (Alexander et al. 2002; García-Serrano et al. 2017).
In this study, we first analyze the observational data in Sect. 3. We then compare the performance of the CMIP5 models in simulating the observed teleconnections and the two mechanisms (Sect. 4). The data sets and methodologies used in this study are described in Sect. 2. Section 5 presents conclusions and discusses the findings of this study.

\section{Data sets and methods}

The observational and reanalysis data sets used in this study include: (1) the NCEP-NCAR reanalysis (Kalnay et al. 1996) that provides the monthly means of air temperature and three-dimensional winds on a $2.5^{\circ} \times 2.5^{\circ}$ grid, as well as surface radiation fluxes on a T62 Gaussian grid; (2) the Hadley Centre Sea Ice and Sea Surface Temperature (HadISST) version 1 data set (Rayner et al. 2003) that provides monthly-mean SSTs on a $1^{\circ} \times 1^{\circ}$ grid; (3) the National Oceanic and Atmospheric Administration Extended Reconstructed SST (NOAA ERSST) version 5 data set (Huang et al. 2017) that provides monthly-mean SSTs on a $2^{\circ} \times 2^{\circ}$ grid; and (4) the centennial in situ observation-based estimates of the variability of SSTs (COBE SST) data set (Ishii et al. 2005) that provides monthly-mean SSTs on a $1^{\circ} \times 1^{\circ}$ grid. The COBE SST data and the ERSST SST data are used to validate the results yielded by the HadISST SST data. The analysis period in this study is 1958-2004. This period is selected because the post-1958 reanalysis data is more reliable (Kistler et al. 2001) and most of the CMIP5 historical simulations are available up to 2004. Historical simulations from thirty-seven (37) CMIP5 models (Table 1) are also used. We use a patch recovery method (Zienkiewicz and Zhu 1992; Jones 1999) to regrid the CMIP5 outputs to common horizontal grids that match the observation grids. The common grids are a $2.5^{\circ} \times 2.5^{\circ}$ grid for winds and air temperature, a T 62 grid for radiation fluxes, and a $2^{\circ} \times 2^{\circ}$ grid for SST. Anomalies in the observations, reanalysis, and CMIP5 simulations are defined as the deviations from the climatological cycle after the linear trend is removed.

A cold tongue index (CTI) is used to quantify ENSO intensity (Paek et al. 2017), which is defined as the SST anomalies (SSTA) averaged within the tropical eastern-central Pacific between $6^{\circ} \mathrm{N}-6^{\circ} \mathrm{S}$ and $180^{\circ}-90^{\circ} \mathrm{W}$.

We develop a way to quantify the contributions of the $\mathrm{AB}$ and TT mechanisms to the ENSO impacts on the neighboring oceans. In order to induce tropical Indian and Atlantic Ocean SSTAs through these mechanisms, the ENSO events have to disturb atmospheric fields over these oceans. The atmospheric anomalies then induce SSTAs underneath. Based on the "quantification of mediated causal effect" method of Runge et al. (2015), the contribution of the AB or TT mechanism to the ENSO inter-basin teleconnections can be quantified as the product of two regression coefficients 
Table 1 List of the observations and CMIP5 models used in this study and their identifications

\begin{tabular}{|c|c|}
\hline ID & Data set name \\
\hline$\alpha$ & HadISST \\
\hline 0 & ACCESS 1.0 \\
\hline 1 & ACCESS 1.3 \\
\hline 2 & BCC_CSM1.1 \\
\hline 3 & CanESM2 \\
\hline 4 & CMCC-CESM \\
\hline 5 & CMCC-CM \\
\hline 6 & CMCC-CMS \\
\hline 7 & CNRM-CM5 \\
\hline 8 & CNRM-CM5.2 \\
\hline 9 & CSIRO Mk3.6.0 \\
\hline$\Phi$ & FGOALS-s2 \\
\hline A & GFDL CM2.1 \\
\hline B & GFDL CM3 \\
\hline $\mathrm{C}$ & GFDL ESM2G \\
\hline D & GFDL ESM2M \\
\hline $\mathrm{E}$ & GISS-E2-H \\
\hline $\mathrm{F}$ & GISS-E2-H-CC \\
\hline G & GISS-E2-R \\
\hline $\mathrm{H}$ & GISS-E2-R-CC \\
\hline I & HadCM3 \\
\hline $\mathrm{J}$ & HadGEM2-CC \\
\hline K & HadGEM2-ES \\
\hline $\mathrm{L}$ & INM-CM4.0 \\
\hline M & IPSL-CM5A-LR \\
\hline $\mathrm{N}$ & IPSL-CM5A-MR \\
\hline $\mathrm{O}$ & IPSL-CM5B-LR \\
\hline $\mathrm{P}$ & MIROC4h \\
\hline Q & MIROC5 \\
\hline $\mathrm{R}$ & MIROC-ESM \\
\hline S & MIROC-ESM-CHEM \\
\hline $\mathrm{T}$ & MPI-ESM-LR \\
\hline $\mathrm{U}$ & MPI-ESM-MR \\
\hline V & MPI-ESM-P \\
\hline W & MRI-CGCM3 \\
\hline$X$ & MRI-ESM1 \\
\hline $\mathrm{Y}$ & NorESM1-M \\
\hline $\mathrm{Z}$ & NorESM1-ME \\
\hline
\end{tabular}

that separately represent the intensities of the two processes just mentioned. To quantify the contribution of the TT mechanism to the ENSO impacts on tropical Atlantic and Indian Oceans SSTAs, the first regression coefficient $\left(R_{\mathrm{CTI} \rightarrow T_{\text {Trop }}}\right)$ evaluates the direct effect of ENSO on the vertically-averaged (1000-200 $\mathrm{hPa}$ ) tropical tropospheric temperature anomaly $\left(T_{\text {Trop }}\right)$ over the these two oceans, and the second regression coefficient $\left(R_{T_{\text {Trop }} \rightarrow \Delta \mathrm{SSTA}}\right)$ evaluates the direct effect of the mean temperature variation on SSTA tendency ( $\Delta$ SSTA) underneath. We then quantify the TT mechanism's contribution to mediating the effect of ENSO on the remote SST as follows:

$\mathrm{TTM}=R_{\mathrm{CTI} \rightarrow T_{\text {Trop }}} \cdot R_{T_{\text {Trop }} \rightarrow \Delta \mathrm{SSTA}} \cdot$

Seasonal mean values are used in the regression calculations. To calculate the first regression coefficient $\left(R_{\mathrm{CTI} \rightarrow T_{\text {Trop }}}\right)$, we regress the seasonal means of the tropical tropospheric mean temperature anomalies over the tropical Atlantic or Indian Ocean region at zero-to-seven-month lag time onto the November-December-January (NDJ) values of the CTI. This means the tropospheric temperature values are the seasonal values taken from NDJ (i.e., zero lag time) up to the following June-July-August (i.e., 7-month lag time). Here, the NDJ is the typical peak season of ENSO. The largest value of these regression coefficients is used as the $R_{\mathrm{CTI} \rightarrow T_{\text {Trop }}}$ in Eq. (1). To calculate the second regression coefficient ( $R_{T_{\text {Trop }} \rightarrow \Delta \text { SSTA }}$ ), we regress the SSTA tendency in the tropical Atlantic or Indian Ocean region onto the overlying tropospheric mean temperature anomalies at the same season. We also calculate the simultaneous regression from NDJ to the following June-July-August and use the largest regression coefficient as the $R_{T_{\text {Trop }} \rightarrow \Delta \text { SSTA }}$ in Eq. (1). To calculate the SSTA tendency, we apply a centered finite difference operator to monthly data and then compute the seasonal means.

A similar procedure is used to quantify the contribution of the $\mathrm{AB}$ mechanism as follows:

$\mathrm{ABM}=R_{\mathrm{CTI} \rightarrow U_{\text {Surf }}} \cdot R_{U_{\text {Surf }} \rightarrow \Delta \mathrm{SSTA}}+R_{\mathrm{CTI} \rightarrow F_{\text {Rad }}} \cdot R_{F_{\text {Rad }} \rightarrow \Delta \mathrm{SSTA}} \cdot$

Here, we replace $T_{\text {Trop }}$ with surface wind speed ( $\left.U_{\text {Surf }}\right)$ and surface radiative flux anomalies $\left(F_{R a d}\right)$ as the key atmospheric fields of the AB mechanism. We utilize these two atmospheric factors because the $\mathrm{AB}$ mechanism can influence SSTA tendencies in the tropical Atlantic or Indian Ocean through both surface sensible and latent heat fluxes (Xie and Philander 1994; Talley et al. 2011) and surface radiative fluxes (Ramanathan and Collins 1991; Klein et al. 1999; Wang 2002). Surface wind speeds play a key role in determining the magnitude of surface sensible and latent heat fluxes. The two regression coefficients in each righthand-side term of Eq. (2) are calculated in the same way as those in Eq. (1).

\section{ENSO inter-basin teleconnections in the observations}

To examine the ENSO inter-basin teleconnections, we regress the February-March-April global SSTAs onto the preceding NDJ values of the CTI using the HadISST data set (Fig. 1a). The figure shows that three months after the El Niño peaks in the Pacific, substantial warming appears 

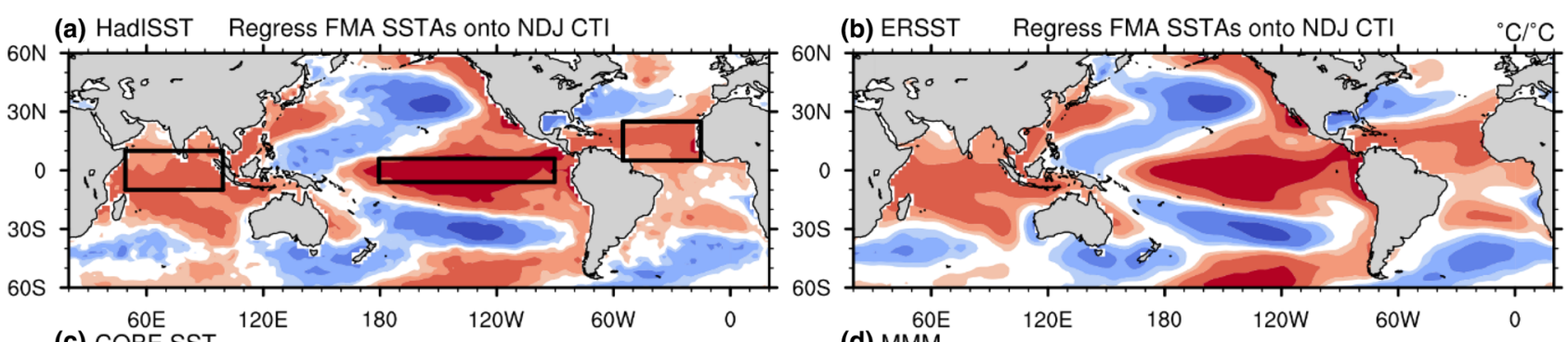

(c) COBE SST

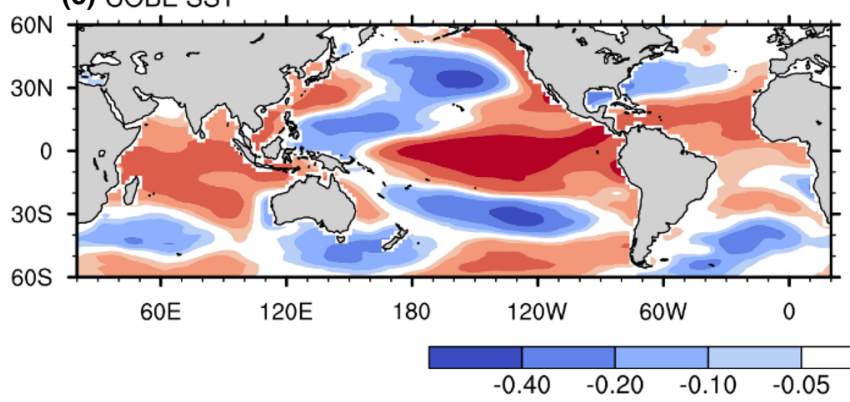

(d) MMM

(e) $\mathrm{TIO}$

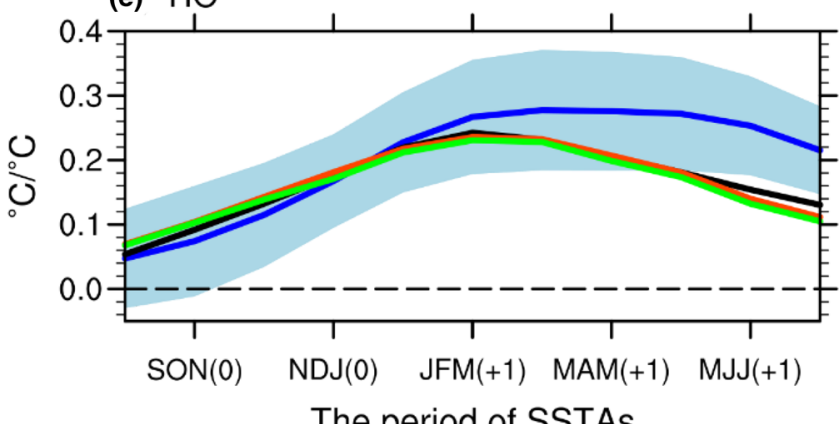

The period of SSTAs
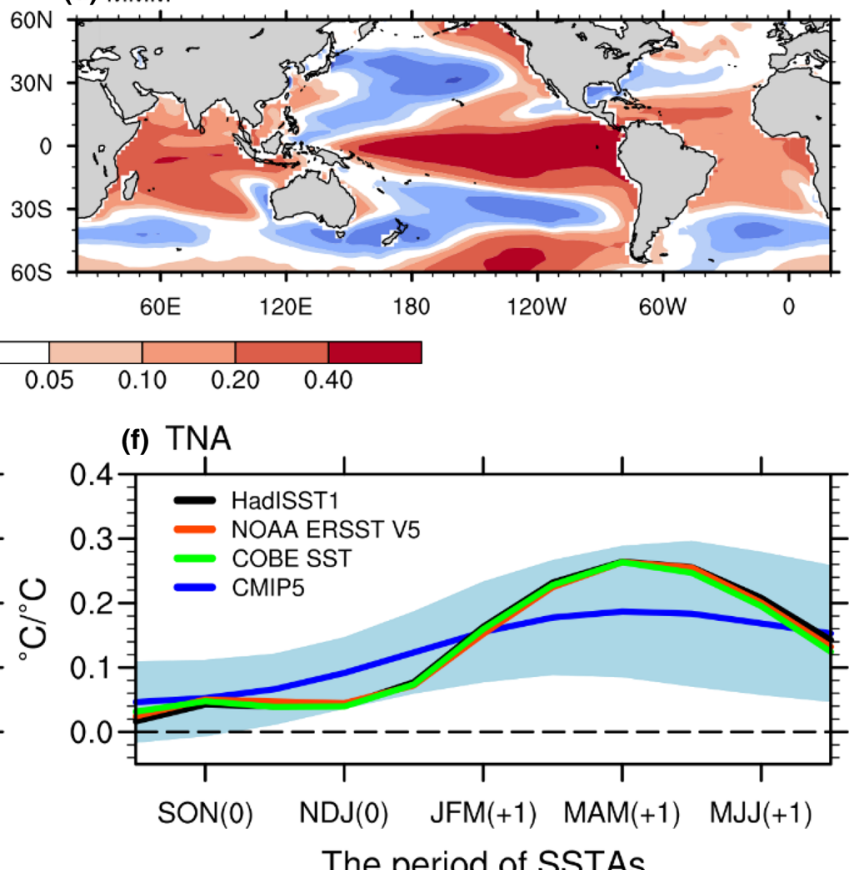

Fig. 1 a-d Regressions of February-April SSTAs onto the NDJ CTI. The lead-lagged regressions of the seasonal SSTAs averaged over the e TIO and the $\mathbf{f}$ TNA onto the NDJ CTI. a The boxes from west

in the tropical Indian and Atlantic Oceans as well as in the South Atlantic and southeastern Indian Oceans. The strongest tropical warming is located along the equator in the Indian Ocean and to the north of the equator in the Atlantic. We define a tropical Indian Ocean (TIO; $10^{\circ} \mathrm{N}-10^{\circ} \mathrm{S}$ and $50^{\circ} \mathrm{E}-100^{\circ} \mathrm{E}$ ) index and a tropical North Atlantic (TNA; $5^{\circ} \mathrm{N}-25^{\circ} \mathrm{N}$ and $15^{\circ} \mathrm{W}-55^{\circ} \mathrm{W}$ ) index to represent the SST variations in these two regions and calculate their lead-lagged regressions onto the NDJ CTI values. As shown in Fig. 1e, $\mathrm{f}$, the TIO response to ENSO peaks two months earlier than the TNA response. These evolutional features are consistent with those found in previous studies (Klein et al. 1999; Alexander et al. 2002; Wang 2002). We repeat the analyses with another two reanalysis SST products (the COBE SST and ERSST data sets) and obtain similar inter-basin teleconnections (Fig. 1b, c).

Figure 1e, f indicates that the peak SST response in the TNA is slightly stronger than that in the TIO. This asymmetric feature is evident when we compare the peak responses in

to east define the TIO, CTI, and TNA regions, respectively. e, f The inter-model standard deviations (cerulean shading) are also shown

Fig. 2a. The difference between the two responses is statistically significant at $40 \%, 35 \%$, and $30 \%$ level in the HadISST, ERSST, and COBE SST data sets, respectively, when one response value is beyond the confidence limit of the other response value. In the rest of the study, we describe only the results obtained from the HadISST data set, unless otherwise mentioned. To examine the contributions of the $\mathrm{AB}$ and $\mathrm{TT}$ mechanisms to this asymmetry, we examine the intensities of the two mechanisms using Eqs. (1) and (2). Figure $2 b$ indicates that the $\mathrm{AB}$ mechanism produces a larger asymmetry between the TIO and TNA regions than the TT mechanism. Specifically, the AB mechanism induces a SST tendency change in the TNA $\left(0.0924{ }^{\circ} \mathrm{C} /{ }^{\circ} \mathrm{C}\right)$ that is 6.4 times that in the TIO $\left(0.0145{ }^{\circ} \mathrm{C} /{ }^{\circ} \mathrm{C}\right)$, while the TT mechanism induces an SST tendency change in the TNA $\left(0.0621^{\circ} \mathrm{C} /{ }^{\circ} \mathrm{C}\right)$ that is 2.5 times that in the TIO $\left(0.0253{ }^{\circ} \mathrm{C} /{ }^{\circ} \mathrm{C}\right)$. As shown in Eq. (2), the $\mathrm{AB}$ mechanism relies on surface wind speed and radiative flux anomalies to produce the ENSO impacts. We find from Fig. $2 b$ that the surface wind speed process contributes 

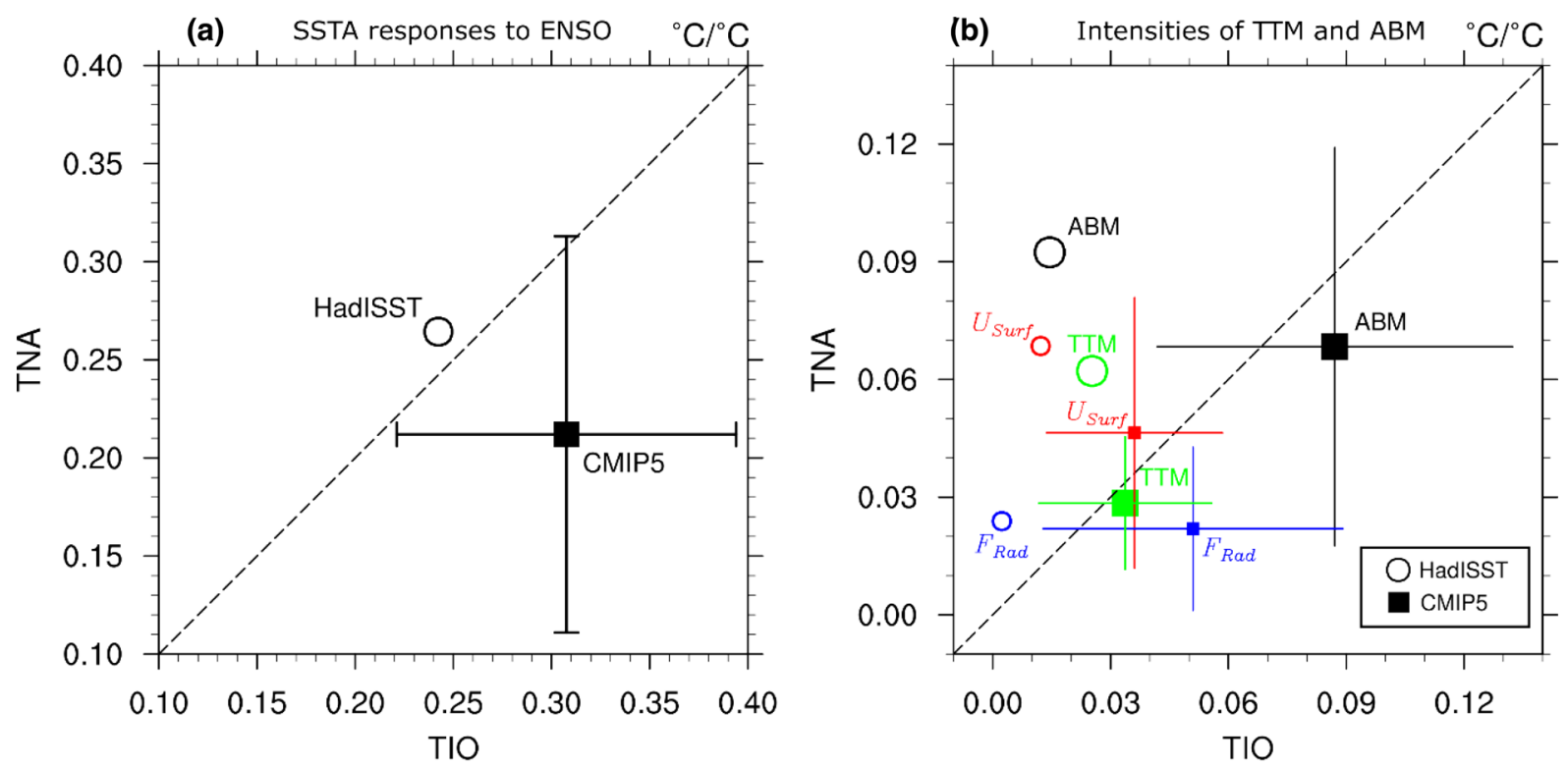

(c) Atmospheric responses to ENSO
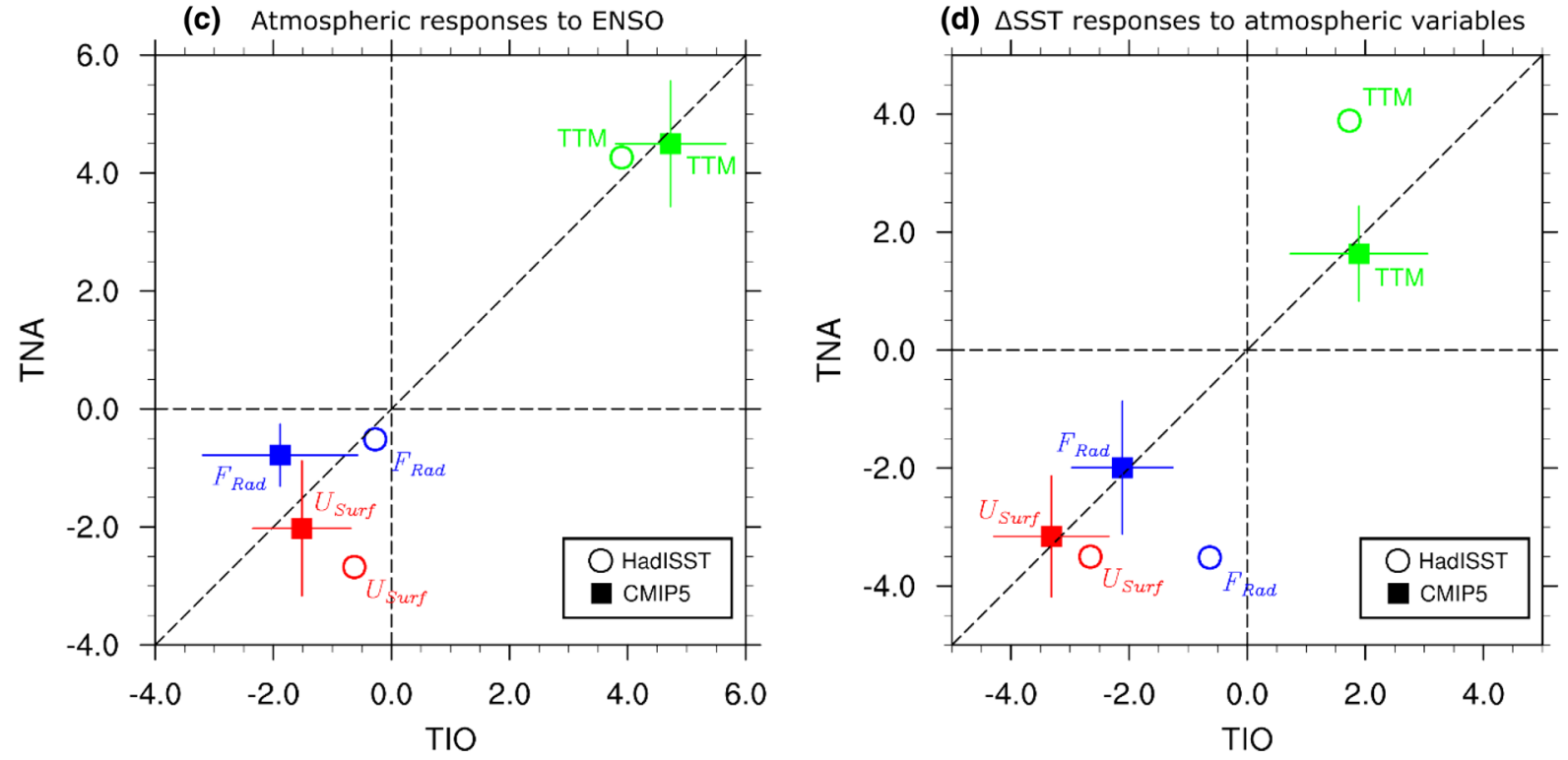

Fig. 2 a The largest cross-lagged regressions of the area averages of seasonal SSTAs onto the NDJ CTI (black). b The intensities of the TT mechanism (TTM; green) and the AB mechanism (ABM; black) including its two subcomponents related to not only surface wind speed $\left(U_{\text {suf }}\right.$; red) but also surface radiative flux $\left(F_{\text {Rad }}\right.$; blue). The values shown here are the products of $\mathbf{c}$ and $\mathbf{d}$. $\mathbf{c}$ The largest cross-lagged

more than the radiative flux process to producing the asymmetric ENSO impacts. We repeat these analyses with the COBE SST and ERSST data sets and obtain similar results (not shown).

We further examine the two sub-processes in the $\mathrm{AB}$ and TT mechanisms, namely the ENSO impacts on the atmospheric fields over the two oceans (Fig. 2c) and the impacts of the atmospheric fields on local SST tendency (Fig. 2d). For the TT mechanism, ENSO produces comparable impacts regressions of the area averages of the three seasonal atmospheric variables onto the NDJ CTI. d The largest simultaneous regressions of the area averages of seasonal SSTA tendencies onto the three local variables. The whiskers represent the inter-model standard deviations. c, $\mathbf{d}$ For visualization, the values are divided by the root mean squares of the standard deviations of the variables over the two oceans

on tropical tropospheric mean temperatures over the TNA and TIO (Fig. 2c). This symmetric feature exists because the ENSO influences spread throughout the tropical troposphere rapidly via Rossby and Kelvin waves (Charney 1963; Sobel et al. 2001; Chiang and Sobel 2002). These wave responses can be seen in Fig. 3, in which we regress the tropospheric mean temperature anomalies at one- and seven-month lags onto the NDJ CTI. At the one-month lag (Fig. 3a), a Rossby wave response is seen as a pair of tropospheric temperature 

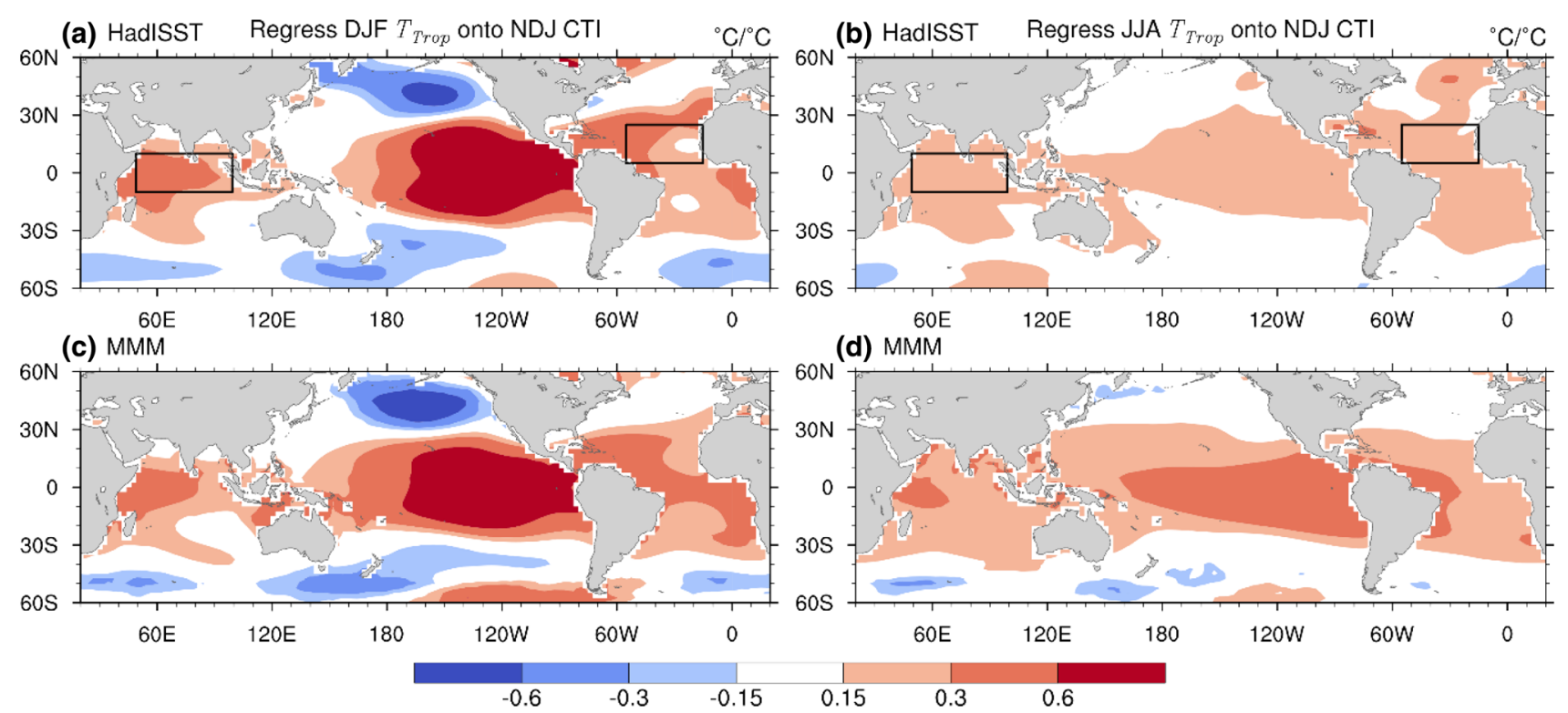

Fig. 3 The regressions of a, $\mathbf{c}$ December-February and $\mathbf{b}, \mathbf{d}$ June-August tropospheric mean temperature anomalies onto the NDJ CTI. a, b The boxes from west to east define the TIO and TNA regions, respectively

anomalies to the west of the ENSO SSTAs, while a Kelvin wave response is seen as temperature anomalies over the equatorial Atlantic to Indian Ocean. At a lag of seven months (Fig. 3b), the wave propagation has produced uniform temperature anomalies throughout the tropical troposphere.

However, as shown in Fig. 2d, the comparable tropospheric temperature anomalies induce a larger SST tendency change in the TNA $\left(0.161{ }^{\circ} \mathrm{C} /{ }^{\circ} \mathrm{C}\right)$ than that in the TIO $\left(0.072{ }^{\circ} \mathrm{C} /{ }^{\circ} \mathrm{C}\right)$. This difference implies that the atmospheric thermal forcing (i.e., atmospheric heat flux) is a more dominant factor in determining the SSTA tendency change in the TNA than in the TIO. This feature supports the suggestions from previous studies that the TNA SSTs are more controlled by atmospheric thermal forcing (e.g., Alexander et al. 2002; Deser et al. 2010), whereas the TIO SSTs are additionally influenced by other factors such as ocean dynamics (e.g., Shinoda et al. 2004; Du et al. 2009; Wu and Yeh 2010). Therefore, the impacts exerted by the TT mechanism on SSTs are asymmetric between the two ocean regions, although the mechanism induces similar atmospheric responses. Statistical significance tests verify the features of the TT mechanism discussed above (see the two leftmost bars in Figs. 4a, 5a).

The different thermal controls also affect how the $\mathrm{AB}$ mechanism produces SSTAs in the TIO and TNA, particularly through surface radiative fluxes. Note that surface heat fluxes are defined as positive upward in Fig. 2. We find that the $\mathrm{AB}$ mechanism produces comparable anomalies in surface radiative fluxes over the two regions (Fig. 2c), but the anomalous radiative fluxes induce a larger SSTA tendency change in the TNA than in the TIO (Fig. 2d). Therefore, the TIO SSTA tendency is not that sensitive to radiative flux, supporting the suggestion that the TIO SSTs are less thermally controlled than the TNA SSTs. In terms of surface wind speed variations, the $\mathrm{AB}$ mechanism produces larger anomalies over the TNA than over the TIO (Fig. 2c), but the anomalous wind speeds induce comparable SSTA tendency changes in both ocean regions (Fig. 2d). Statistical significance tests verify the features of the $\mathrm{AB}$ mechanism discussed above (see the two leftmost bars in Figs. 4b, c, 5b, c).

The surface wind responses to ENSO over the neighboring oceans are related to how the Walker circulation is displaced during the ENSO events. To examine this displacement, we regress December-January-February omega anomalies onto the NDJ CTI (Fig. 6). Note that tropical surface wind anomalies can be visually inferred from the anomalous vertical motions, to which the divergent motions are closely connected (Holton and Hakim 2013). Figure 6a shows that, in the case of El Niño, an anomalous sinking motion occurs to the west of the CTI region, covering the tropical western Pacific and part of the TIO. The regressions of surface wind and surface wind speed anomalies onto the NDJ CTI are shown in Fig. 7a. As shown in this figure, the sinking motion induces surface easterly anomalies over the TIO that attenuate the equatorial westerlies and reduce surface wind speeds. Over the tropical Atlantic, the ENSO events also produce anomalous descent to the east of the eastern Pacific, which covers most of the tropical Atlantic (Fig. 6a). Figure 6b shows that the tropical anomalous descent further generates secondary circulation anomalies to its north. As a result, anomalous southwesterlies prevail over the TNA, counteracting the northeasterly trades and 

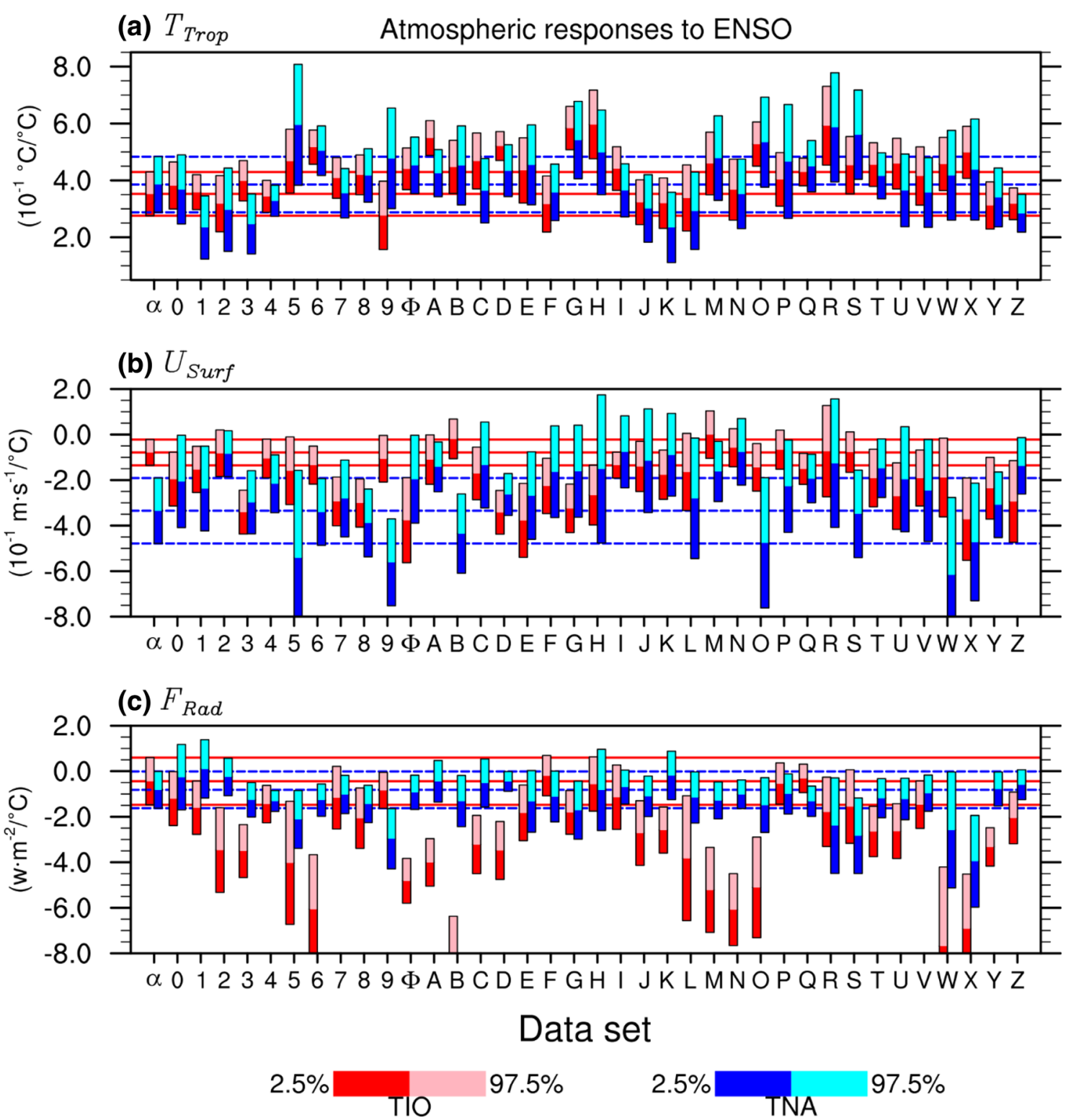

Fig. 4 The largest cross-lagged regressions of the area averages of the three seasonal atmospheric variables onto the NDJ CTI and their 95\% confidence intervals. The two leftmost bars and the dashed lines denote the observed values obtained from the HadISST data set

diminishing surface wind speeds (Fig. 7a). Similar features are observed in the following spring (not shown). This secondary circulation impact explains why the largest SSTA response to ENSO in the tropical Atlantic occurs to the north of the equator. In addition, the extratropical atmospheric process (i.e., the Pacific-North American pattern pattern) also contributes to the TNA SST response to ENSO (Giannini et al. 2000). It is evident in Fig. 6a that the anomalous Walker circulation during ENSO extends further into the tropical Atlantic than over the TIO. This asymmetric ENSO impact on the Walker circulations causes a stronger ENSO impact on the surface wind speeds over the TNA than over the TIO.
Our analyses (in Figs. 2, 3, 4, 5, 6, 7) indicate that the asymmetric responses of TNA and TIO SSTAs to ENSO result from two major causes. One is that the SSTs in the TNA are more controlled by atmospheric thermal forcing than the SSTs in the TIO, rendering the comparable tropospheric mean temperature anomalies induced by the TT mechanism and the comparable surface radiative flux anomalies induced by the $\mathrm{AB}$ mechanism less effective in changing SSTs in the TIO than in the TNA. The other is that the ENSO-induced Walker circulation anomalies extend further into the TNA than the TIO. Due to its close connection to the anomalous Walker circulation, the AB mechanism (through its impact on surface wind speeds in particular) is 


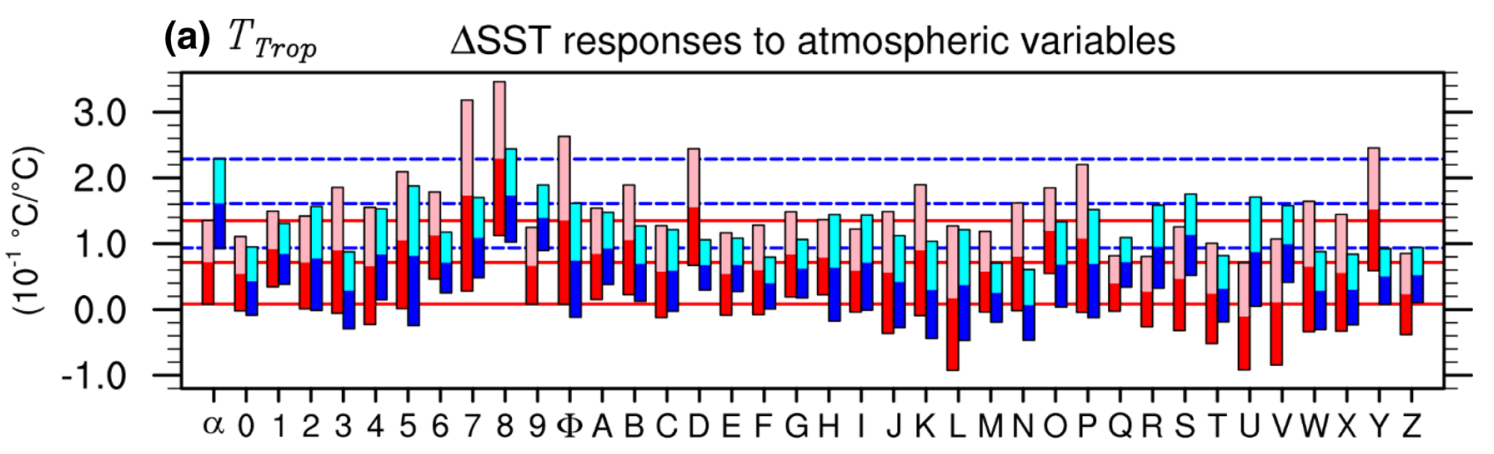

(b) $U_{\text {Surf }}$

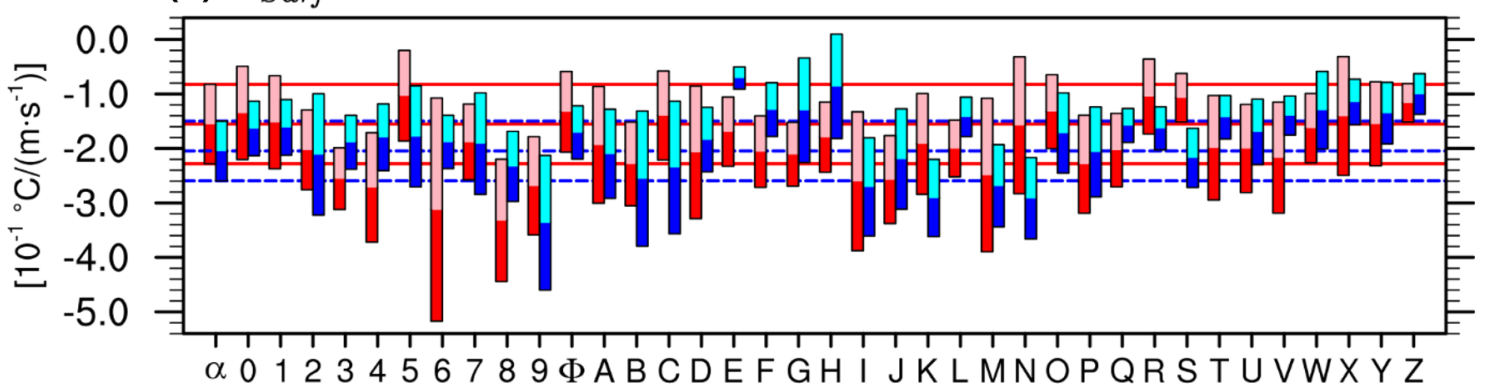

(c) $F_{\text {Rad }}$

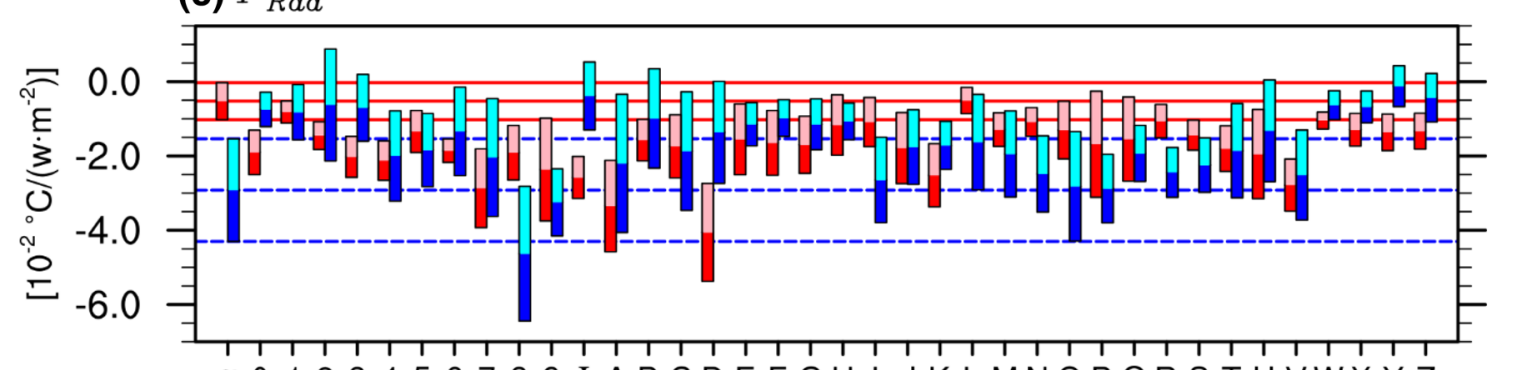

a 0123456789 AABCDEFGH I JKLMNOPQRSTUVWXYZ

Data set

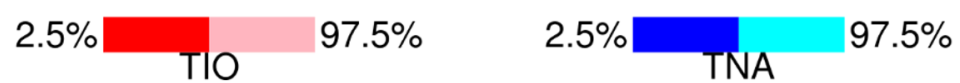

Fig. 5 As in Fig. 4, except for the largest simultaneous regressions of the area averages of seasonal SSTA tendencies onto the three local variables

the dominant contributor to the asymmetric ENSO effects on the SSTs between the two oceans.

\section{ENSO inter-basin teleconnections in CMIP5 model simulations}

We use the multi-model mean (MMM) values calculated from the historical simulations of 37 CMIP5 models to examine how effectively the CMIP5 models simulate the $\mathrm{TT}$ and $\mathrm{AB}$ mechanisms and the resultant SSTA responses in the TIO and the TNA. The MMM values of the three-month lagged regressions of model SSTAs onto the NDJ CTI are shown in Fig. 1d. The figure indicates that the CMIP5 models reproduce the observed SSTA responses in the TIO and the TNA during the ENSO events. The simulated responses reach a maximum in the TIO and TNA about three to four months after ENSO peaks (Fig. 1e, f). However, in contrast to the observations, the simulated TIO warming, in the case of El Niño, is overestimated and lingers longer, whereas the simulated TNA warming is underestimated. The CMIP5 models produce asymmetric ENSO responses between the TNA and the TIO that are statistically significant at 5\% level (Fig. 8), but the simulated asymmetry is opposite from the observed asymmetry. This difference is clearly revealed in Fig. 2a, which shows that the peak TIO and TNA responses 

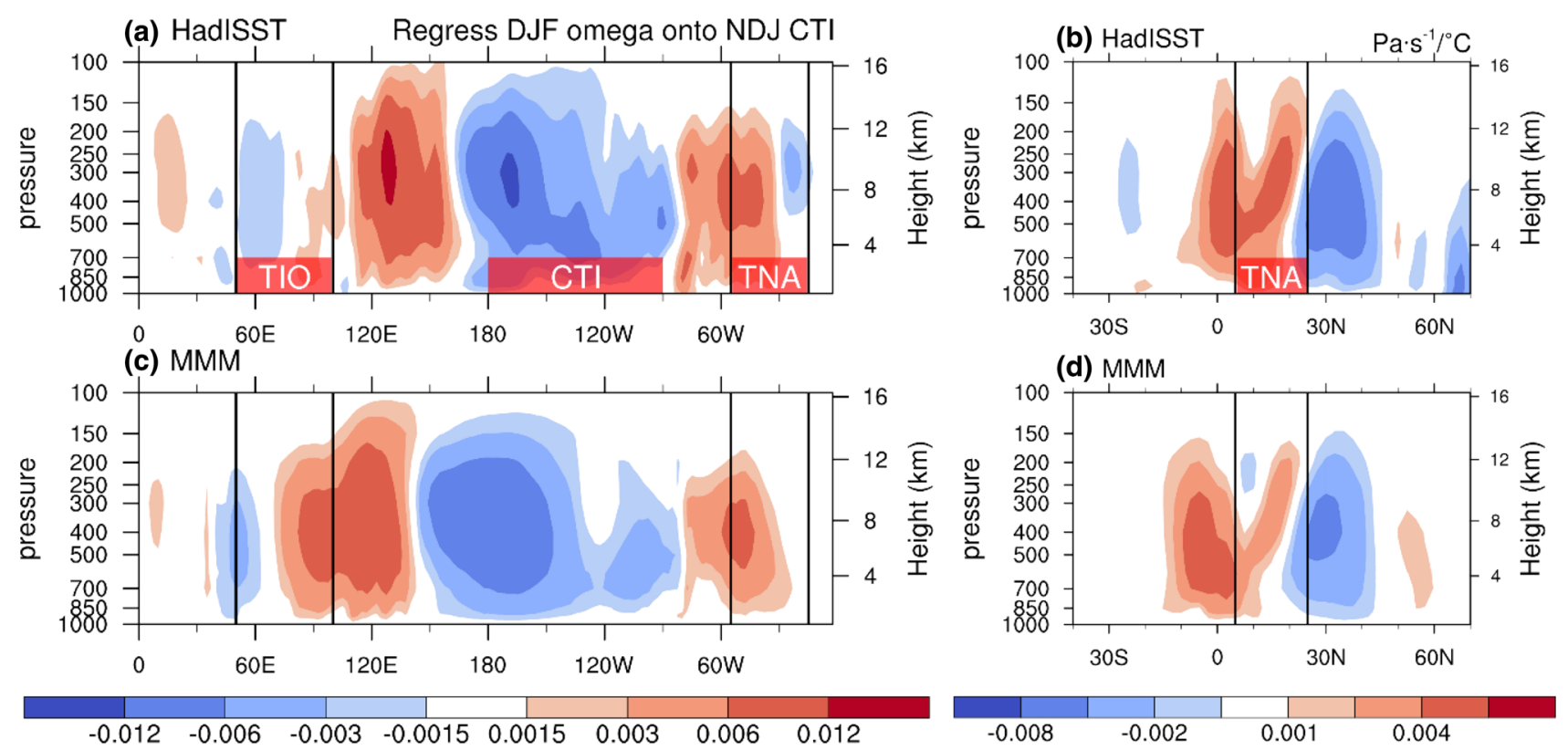

Fig. 6 The regressions of the December-February omega anomalies averaged $\mathbf{a}$, c between $15^{\circ} \mathrm{N}$ and $15^{\circ} \mathrm{S}$ or $\mathbf{b}$, $\mathbf{d}$ between $15^{\circ} \mathrm{W}$ and $55^{\circ} \mathrm{W}$ onto the NDJ CTI in the a, b observations and $\mathbf{c}, \mathbf{d}$ CMIP5 MMM

(a) HadISST Regress DJF $U_{\text {Surf }}$ onto NDJ CTI

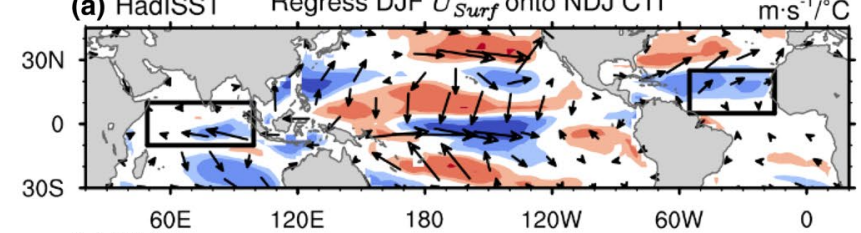

(c) MMM

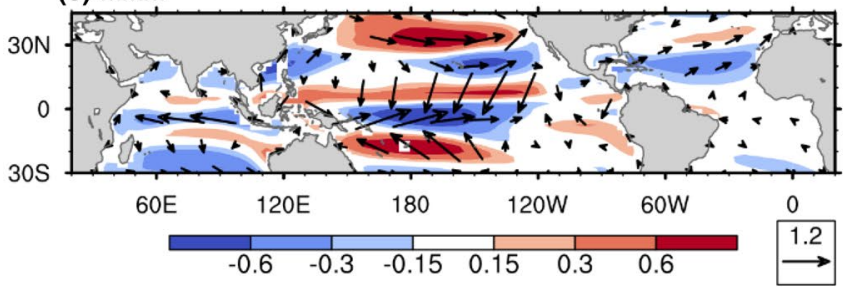

(b) HadISST Regress DJF $F_{\text {Rad }}$ onto NDJ CTI_ $\quad \mathrm{w} \cdot \mathrm{m}^{-2} /{ }^{\circ} \mathrm{C}$

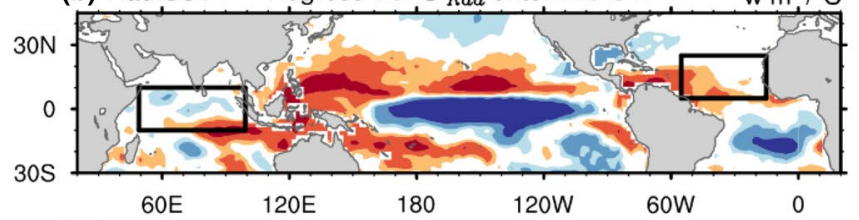

(d) MMM

Fig. 7 The regressions of December-February a, $\mathbf{c}$ surface wind (vectors), surface wind speed (colors), and $\mathbf{b}$, $\mathbf{d}$ surface radiative flux anomalies onto the NDJ CTI. a, b The boxes from west to east define the TIO and TNA regions, respectively

to ENSO in the observations and in the MMM lie on opposite sides of the $45^{\circ}$ diagonal line. This shortcoming of the CMIP5 simulations can have many implications. For example, it implies that the CMIP5 models produce an overly strong capacitor effect of the Indian Ocean, which is an important component of the delayed ENSO impact on the western Pacific and East Asian weather and climate (e.g., Xie et al. 2009, 2016; Liu et al. 2018). Previous studies have also shown that only during the boreal summer of the decaying phase of ENSO will TIO SSTAs exert a significant impact on the western North Pacific anomalous anticyclone (Wu et al. 2009, 2010; Chen et al. 2019). The anomalous anticyclone can modulate surface zonal winds in the tropical western Pacific, speeding up or slowing down the termination or transition of ENSO. Therefore, an overestimation of the TIO SST response to ENSO can also influence the performance of the CMIP5 models in simulating ENSO evolution and diversity (Capotondi et al. 2015; An and Kim 2018; Timmermann et al. 2018; Chen et al. 2019). Figure 8 shows that more than one-third of the models significantly overestimate the SST responses to ENSO in the TIO. Regarding the SST responses to ENSO in the TNA, there are also more than one-third of the models which significantly underestimate the responses. 

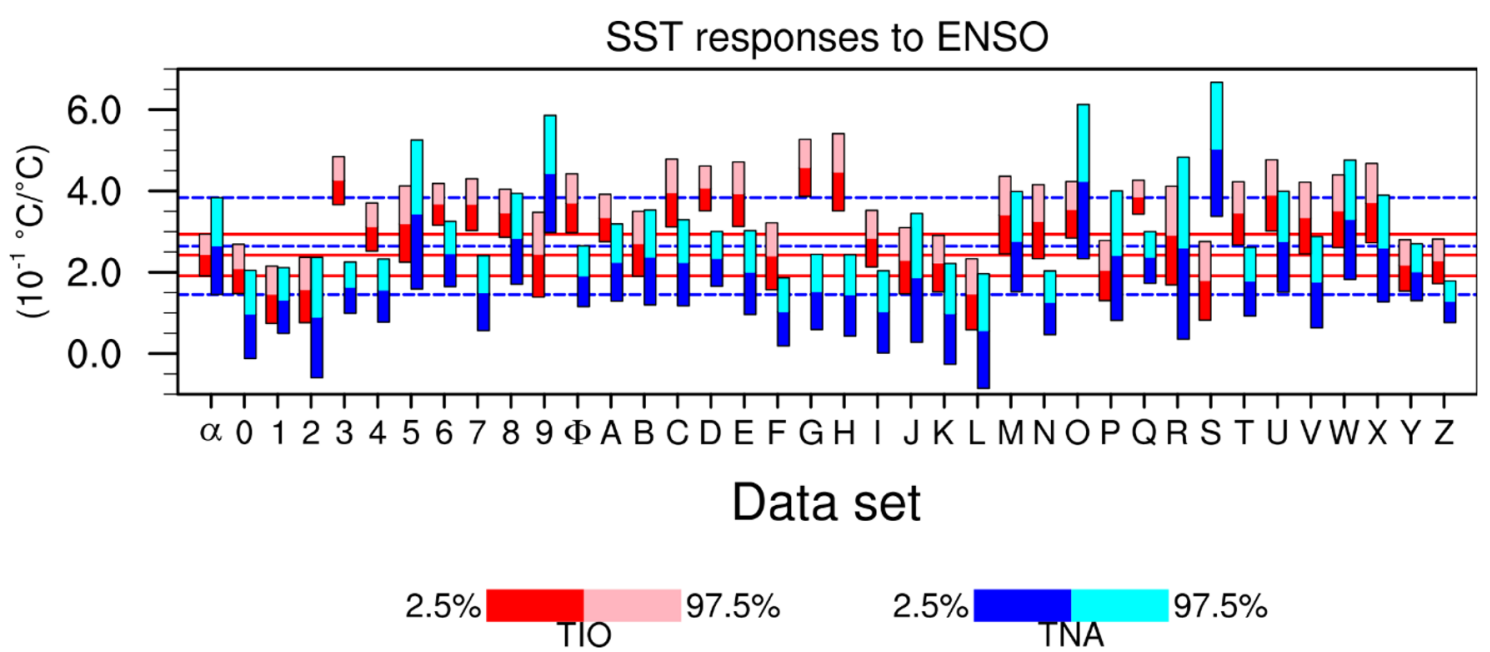

Fig. 8 As in Fig. 4, except for the largest cross-lagged regressions of the area averages of seasonal SSTA onto the NDJ CTI

We explore the causes of the erroneous asymmetry in the CMIP5 models by examining their simulations of the $\mathrm{AB}$ and TT mechanisms. For this purpose, we apply the previous mechanism analyses (see Fig. 2) to all 37 CMIP5 models, after which, we compare their MMM values with the observed values in the same figure. Figure $2 b$ shows that the simulated TT mechanism is comparable to that observed in the TIO but underestimated in the TNA, while the simulated $\mathrm{AB}$ mechanism is comparable to that observed in the TNA but overestimated in the TIO. The overly weak TT mechanism in the TNA and the overly strong AB mechanism in the TIO are the key causes for the erroneous model simulations of the TNA and TIO responses to ENSO. For the simulated TT mechanism, we find that the CMIP5 models reasonably simulate the tropospheric temperature responses to ENSO (Figs. 2c, 3), but the impact of the tropospheric temperature on the SSTA tendency is underestimated in the TNA (Figs. 2d, 3). Over one-third of the models significantly underestimate the effect of the tropospheric temperature anomalies over the TNA on the underneath SSTA tendency (Fig. 5a). Therefore, the underestimated TT mechanism in the TNA is caused by the underestimated impact of tropospheric temperature on the TNA SSTs rather than the ENSO impact on the tropospheric temperature. The underestimated effect of tropospheric mean temperature on the SSTA tendency is likely to arise from an overestimation of ocean mixed layer depths in the tropical Atlantic Ocean in many ocean models (Noh and Lee 2008; Zhang et al. 2018).

Regarding the $\mathrm{AB}$ mechanism, both radiative fluxes and surface wind processes contribute to the overestimated $\mathrm{AB}$ mechanism in the TIO (Fig. 2b). We find that the MMM has overly strong ENSO impacts on surface radiative fluxes and wind speeds over the TIO (Fig. 2c). The TIO SSTA tendency also displays a stronger sensitivity to surface radiative flux anomalies in the CMIP5 models than in the observations (Fig. 2d). Why is the simulated $\mathrm{AB}$ mechanism overestimated in the TIO? We find that the ENSO-induced anomalous subsidence in the MMM is over the Maritime Continent rather than over the western Pacific as in the observations (Fig. 6a, c). As a result, the ENSO-induced subsidence, the associated radiative flux, and easterly anomalies cover a much larger area of the TIO in the MMM (Fig. 7c, d) than in the observations (cf. Figure $7 \mathrm{a}, \mathrm{b}$ ). The overestimation of the ENSO impacts on wind speeds and radiative fluxes in the CMIP5 models can be attributed to this erroneously westward extension of the ENSO-induced anomalous Walker circulation. In Fig. 9, we regress the equatorial Pacific SSTAs onto the NDJ CTI to compare the observed and simulated SSTA evolutions during ENSO. Obviously, the simulated ENSO SSTAs extend further westward than the observed ones, explaining why the simulated Walker circulation anomalies extend too far westward over the Indian Ocean.

The significance tests show that over one-third of the CMIP5 models examined significantly overestimate the ENSO effects on the surface wind speed (Fig. 4b) and surface radiative fluxes (Fig. 4c) over the TIO, while over one-third of the models significantly overestimate the TIO SSTA tendency's sensitivity to surface radiative flux anomalies (Fig. 5c).

Overall, compared with the observations, the overly westward-extended ENSO SSTAs in the models intensify the AB mechanism over the TIO. As a result, the ENSO impact on TIO SSTs is overestimated. Meanwhile, an overestimation of the thermal inertia in the upper ocean of the TNA may lead to the underestimation of the ENSO impact on TNA SSTs. 


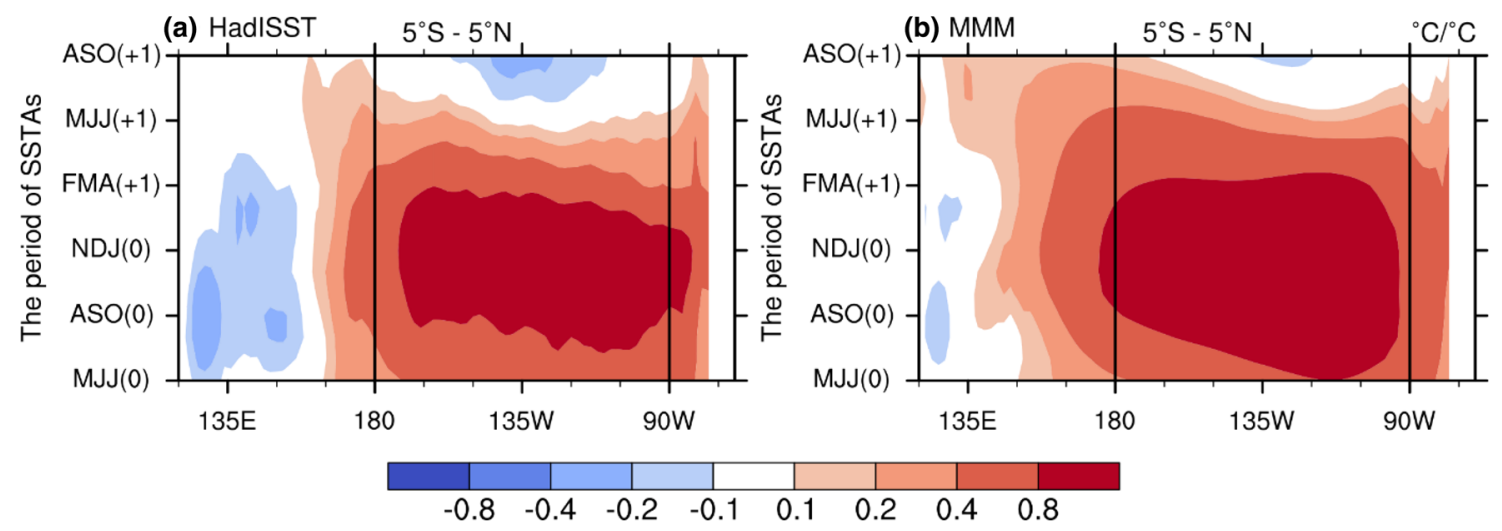

Fig. 9 Hovmoller diagram of the cross-lagged regressions of seasonal SSTAs onto the NDJ CTI. The SSTAs are averaged from $5^{\circ} \mathrm{N}$ to $5^{\circ} \mathrm{S}$. The vertical lines show the longitudes of the CTI region

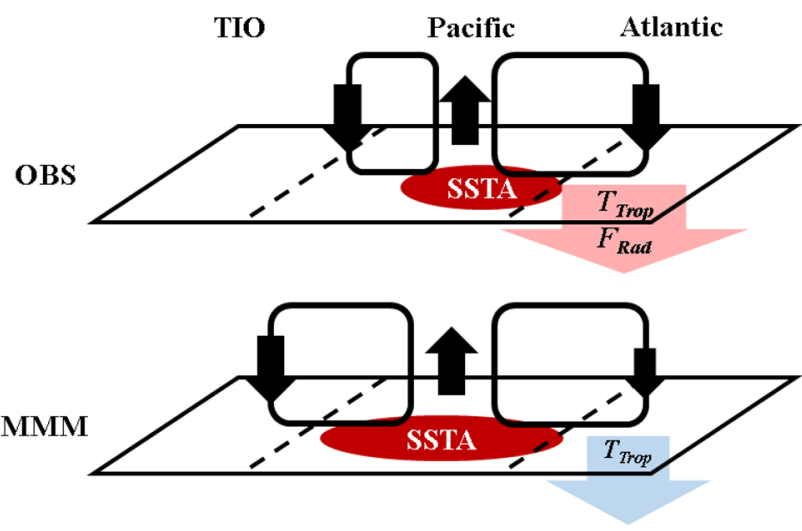

Fig. 10 Schematic diagram illustrating the causes of the asymmetric SST response to ENSO in the TIO and TNA in the (top) observations and (bottom) CMIP5 MMM. The red arrow denotes the more dominant influences of thermal factors on the TNA than on the TIO; the blue arrow denotes the less dominant influences of thermal factors on the TNA in the MMM than in the observations; the red ellipse denotes the ENSO SSTAs. The black arrows represent the vertical motion responses to El Niño, and vice versa in the case of La Niña

\section{Conclusions}

In this study, we have examined the impacts of ENSO on the SSTAs over the tropical Atlantic and Indian Oceans and the relative contributions of two atmospheric mechanisms to these impacts. We have also analyzed the CMIP5 historical simulations to determine their reliability in simulating the observed impacts and mechanisms.

The main findings are summarized in Fig. 10. In the observations, ENSO produces a slightly stronger impact on the TNA SSTAs via the AB and TT mechanisms than on the TIO SSTAs. Two major factors lead to the asymmetric impacts. One is that the ENSO-induced anomalous Walker circulation extends further into the tropical
Atlantic than into the TIO, which enables the $\mathrm{AB}$ mechanism to produce stronger thermal forcing in the Atlantic than in the Indian Ocean. The other is the different relative controls of atmospheric thermal forcing over the SST changes in these two oceans. The SSTA tendency in the TNA is found to be more sensitive to thermal forcing than that in the TIO. As a result, the AB mechanism is a substantial contributor to the asymmetry in the ENSO impacts on the TNA and TIO. The TT mechanism also exerts an asymmetric ENSO impact on the two oceans. This mechanism produces symmetric influences on the tropospheric temperature over the TNA and the TIO, but the TNA's stronger sensitivity to this thermal forcing (compared to the TIO) results in a stronger ENSO impact on the TNA SSTAs than on the TIO SSTAs.

The MMM of the CMIP5 models overestimates the ENSO impacts on the TIO and underestimates the impacts on the TNA. Our analyses indicate that the overestimated impact on the TIO results from an erroneously westward extension of the simulated ENSO SSTAs, which displaces the ENSO-induced anomalous Walker circulation further toward the Indian Ocean than observed. This erroneously westward circulation then intensifies the ENSO impact on the TIO through the AB mechanism. On the other hand, the underestimated ENSO impact on the TNA mainly arises from a weaker-than-observed TT mechanism over this ocean in the CMIP5 models. The models do reproduce an authentic ENSO impact on the tropospheric temperature over the TNA region, but the TNA SSTAs in the models show a weaker sensitivity to these tropospheric temperature anomalies than the observed. The weaker sensitivity may result from the erroneous mixed layer depths of the tropical Atlantic simulated in the models.

In observations, the asymmetry in the SST response to ENSO between the TNA and TIO is not as large as the asymmetry in the intensities of the $\mathrm{AB}$ and TT mechanisms over 
these two oceans (Fig. 2b). Therefore, there must be other factors affecting the ENSO impacts on the two oceans, such as extratropical atmospheric processes, ocean dynamics, and coupled atmosphere-ocean processes. We, however, do not quantify these oceanic factors due to the scope of this study, and thus, further studies on this topic are needed. Also, it should be noted that we assess in this study the overall performance of the CMIP5 models. Inter-model diversities exist in the simulations of oceanic responses to ENSO (e.g., Du et al. 2013).

Acknowledgements The authors thank Dr. Jianhua Lu, Dr. Wenxiu Zhong and the two anonymous reviewers for their invaluable suggestions and inspiring comments. Gratitude also goes to Ms. Ge Tang who helped polish the present paper. This study was supported by the National Key Research and Development Program of China (2016YFA0602703), the National Natural Science Foundation of China (Grants 41690123, 41690120 and 91637208), the Jiangsu Collaborative Innovative Center for Climate Change of China, the Guangzhou Institute of Tropical and Marine Meteorology/Guangdong Provincial Key Laboratory of Regional Numerical Weather Prediction, and the NSF Climate and Large-scale Dynamics Program of US under Grants AGS1505145 and AGS-1833075. The Computational \& Information Systems Laboratory at the National Center for Atmospheric Research provides the NCAR Command Language software. The NCEP-NCAR reanalysis, NOAA ERSST, and COBE SST data sets are obtained from the NOAA/OAR/ESRL PSD at https://www.esrl.noaa.gov/psd/, while the HadISST data set is downloaded from the UK Met Office at https ://www.metoffice.gov.uk.

Open Access This article is licensed under a Creative Commons Attribution 4.0 International License, which permits use, sharing, adaptation, distribution and reproduction in any medium or format, as long as you give appropriate credit to the original author(s) and the source, provide a link to the Creative Commons licence, and indicate if changes were made. The images or other third party material in this article are included in the article's Creative Commons licence, unless indicated otherwise in a credit line to the material. If material is not included in the article's Creative Commons licence and your intended use is not permitted by statutory regulation or exceeds the permitted use, you will need to obtain permission directly from the copyright holder. To view a copy of this licence, visit http://creativecommons.org/licenses/by/4.0/.

\section{References}

Alexander MA, Bladé I, Newman M et al (2002) The atmospheric bridge: the influence of ENSO teleconnections on air-sea interaction over the global oceans. J Clim 15:2205-2231. https ://doi.org/10.1175/1520-0442(2002)015\%3c2205:TABTI $\mathrm{O} \% 3 \mathrm{e} 2.0 . \mathrm{CO} ; 2$

An S-I, Kim J-W (2018) ENSO transition asymmetry: Internal and external causes and intermodel diversity. Geophys Res Lett 45:5095-5104. https://doi.org/10.1029/2018GL078476

Cai W, Wu L, Lengaigne M et al (2019) Pantropical climate interactions. Science 363:eaav4236. https://doi.org/10.1126/scien ce.aav4236

Capotondi A (2015) Extreme La Niña events to increase. Nat Clim Change 5:100-101. https://doi.org/10.1038/nclimate2509
Capotondi A, Wittenberg AT, Newman M et al (2015) Understanding ENSO diversity. Bull Am Meteorol Soc 96:921-938. https://doi. org/10.1175/BAMS-D-13-00117.1

Charney JG (1963) A note on large-scale motions in the tropics. J Atmos Sci 20:607-609. https://doi.org/10.1175/15200469(1963)020\%3c0607:ANOLSM\%3e2.0.CO;2

Chen MY, Yu J-Y, Wang X, Jiang WP (2019) The changing impact mechanisms of a diverse El Niño on the western Pacific subtropical high. Geophys Res Lett 46:953-962. https://doi. org/10.1029/2018GL081131

Chiang JCH, Lintner BR (2005) Mechanisms of remote tropical surface warming during El Niño. J Clim 18:4130-4149. https://doi. org/10.1175/JCLI3529.1

Chiang JCH, Sobel AH (2002) Tropical tropospheric temperature variations caused by ENSO and their influence on the remote tropical climate. J Clim 15:2616-2631. https ://doi.org/10.1175/1520-0442(2002)015\%3c2616:TTTVC B\%3e2.0.CO;2

Chowdary JS, Chaudhari HS, Gnanaseelan C et al (2014) Summer monsoon circulation and precipitation over the tropical Indian Ocean during ENSO in the NCEP climate forecast system. Clim Dyn 42:1925-1947. https://doi.org/10.1007/s00382-013-1826-5

Chowdary JS, Gnanaseelan C (2007) Basin-wide warming of the Indian Ocean during El Niño and Indian Ocean dipole years. Int J Climatol 27:1421-1438. https://doi.org/10.1002/joc.1482

Deser C, Alexander MA, Xie S-P, Phillips AS (2010) Sea surface temperature variability: patterns and mechanisms. Annu Rev Mar Sci 2:115-143. https://doi.org/10.1146/annurev-marin e-120408-151453

Du Y, Xie S-P, Huang G, Hu K (2009) Role of air-sea interaction in the long persistence of El Niño-induced North Indian Ocean warming. J Clim 22:2023-2038. https://doi.org/10.1175/2008J CLI2590.1

Du Y, Xie S-P, Yang Y-L et al (2013) Indian Ocean variability in the CMIP5 multimodel ensemble: the basin mode. J Clim 26:7240 7266. https://doi.org/10.1175/JCLI-D-12-00678.1

Enfield DB, Mayer DA (1997) Tropical Atlantic sea surface temperature variability and its relation to El Niño-Southern Oscillation. J Geophys Res 102:929-945. https://doi.org/10.1029/96JC03296

García-Serrano J, Cassou C, Douville H et al (2017) Revisiting the ENSO teleconnection to the tropical North Atlantic. J Clim 30:6945-6957. https://doi.org/10.1175/JCLI-D-16-0641.1

Giannini A, Kushnir Y, Cane MA (2000) Interannual variability of Caribbean rainfall, ENSO, and the Atlantic Ocean. J Clim 13:297-311. https://doi.org/10.1175/1520-0442(2000)013\%3c029 7:IVOCRE\%3e2.0.CO;2

Gill AE (1980) Some simple solutions for heat-induced tropical circulation. Q J R Meteorol Soc 106:447-462. https://doi.org/10.1002/ qj. 49710644905

Ham Y-G, Kug J-S, Park J-Y, Jin F-F (2013) Sea surface temperature in the North tropical Atlantic as a trigger for El Niño/Southern Oscillation events. Nat Geosci 6:112-116. https://doi.org/10.1038/ ngeo1686

Holton JR, Hakim GJ (2013) Elementary applications of the basic equations. In: Holton JR, Hakim GJ (eds) An introduction to dynamic meteorology, 5th edn. Academic Press, Boston, pp 67-93

Huang B, Thorne PW, Banzon VF et al (2017) Extended reconstructed sea surface temperature, version 5 (ERSSTv5): Upgrades, validations, and intercomparisons. J Clim 30:8179-8205. https://doi. org/10.1175/JCLI-D-16-0836.1

Ishii M, Shouji A, Sugimoto S, Matsumoto T (2005) Objective analyses of sea-surface temperature and marine meteorological variables for the 20th century using ICOADS and the Kobe Collection. Int J Climatol 25:865-879. https://doi.org/10.1002/joc.1169

Jones PW (1999) First- and second-order conservative remapping schemes for grids in spherical coordinates. Mon 
Weather Rev 127:2204-2210. https://doi.org/10.1175/15200493(1999)127\%3c2204:FASOCR\%3e2.0.CO;2

Kalnay E, Kanamitsu M, Kistler R et al (1996) The NCEP/NCAR 40-year reanalysis project. Bull Am Meteorol Soc 77:437-471. https://doi.org/10.1175/1520-0477(1996)077\%3c0437:TNYRP $\% 3 \mathrm{e} 2.0 . \mathrm{CO} ; 2$

Kistler R, Kalnay E, Collins W et al (2001) The NCEP-NCAR 50-year reanalysis: monthly means CD-ROM and documentation. Bull Am Meteorol Soc 82:247-267. https://doi.org/10.1175/15200477(2001)082\%3c0247:TNNYRM\%3e2.3.CO;2

Klein SA, Soden BJ, Lau N-C (1999) Remote sea surface temperature variations during ENSO: evidence for a tropical atmospheric bridge. J Clim 12:917-932. https://doi.org/10.1175/15200442(1999)012\%3c0917:RSSTVD\%3e2.0.CO;2

Kousky VE, Kagano MT, Cavalcanti IFA (1984) A review of the Southern Oscillation: oceanic-atmospheric circulation changes and related rainfall anomalies. Tellus Dyn Meteorol Oceanogr 36:490-504. https://doi.org/10.1111/j.1600-0870.1984.tb00264.x

Kug J-S, Kang I-S (2006) Interactive feedback between ENSO and the Indian Ocean. J Clim 19:1784-1801. https://doi.org/10.1175/JCLI3 660.1

Lau K-M, Lim H (1982) Thermally driven motions in an equatorial betaplane: Hadley and Walker circulations during the winter monsoon. Mon Weather Rev 110:336-353. https://doi.org/10.1175/15200493(1982)110\%3c0336:TDMIAE\%3e2.0.CO;2

Liu B, Zhu C, Su J et al (2018) Why was the western Pacific subtropical anticyclone weaker in late summer after the 2015/2016 super El Niño? Int J Climatol 38:55-65. https://doi.org/10.1002/joc.5160

Liu H, Wang C, Lee S-K, Enfield D (2013) Atlantic warm pool variability in the CMIP5 simulations. J Clim 26:5315-5336. https://doi. org/10.1175/JCLI-D-12-00556.1

Liu L, Xie S-P, Zheng X-T et al (2014) Indian Ocean variability in the CMIP5 multi-model ensemble: the zonal dipole mode. Clim Dyn 43:1715-1730. https://doi.org/10.1007/s00382-013-2000-9

Marengo JA, Nobre CA, Tomasella J et al (2008) The drought of Amazonia in 2005. J Clim 21:495-516. https://doi.org/10.1175/2007J CLI1600.1

Noh Y, Lee W-S (2008) Mixed and mixing layer depths simulated by an OGCM. J Oceanogr 64:217-225. https://doi.org/10.1007/s1087 2-008-0017-1

Ohba M, Ueda H (2005) Basin-wide warming in the equatorial Indian Ocean associated with El Niño. Sci Online Lett Atmos 1:89-92. https://doi.org/10.2151/sola.2005-024

Paek H, Yu J-Y, Qian C (2017) Why were the 2015/2016 and 1997/1998 extreme El Niños different? Geophys Res Lett 44:1848-1856. https ://doi.org/10.1002/2016GL071515

Ramanathan V, Collins W (1991) Thermodynamic regulation of ocean warming by cirrus clouds deduced from observations of the $1987 \mathrm{El}$ Niño. Nature 351:27-32. https://doi.org/10.1038/351027a0

Rasmusson EM, Carpenter TH (1982) Variations in tropical sea surface temperature and surface wind fields associated with the Southern Oscillation/El Niño. Mon Weather Rev 110:354-384. https://doi. org/10.1175/1520-0493(1982)110\%3c0354:VITSST\%3e2.0.CO;2

Rayner NA, Parker DE, Horton EB et al (2003) Global analyses of sea surface temperature, sea ice, and night marine air temperature since the late nineteenth century. J Geophys Res 108:4407. https://doi. org/10.1029/2002JD002670

Runge J, Petoukhov V, Donges JF et al (2015) Identifying causal gateways and mediators in complex spatio-temporal systems. Nat Commun 6:8502. https://doi.org/10.1038/ncomms9502

Schott FA, Xie S-P, McCreary Jr. JP (2009) Indian Ocean circulation and climate variability. Rev Geophys 47:RG1002. https://doi. org/10.1029/2007RG000245

Shinoda T, Alexander MA, Hendon HH (2004) Remote response of the Indian Ocean to interannual SST variations in the tropical Pacific. J Clim 17:362-372. https://doi.org/10.1175/15200442(2004)017\%3c0362:RROTIO\%3e2.0.CO;2

Sobel AH, Nilsson J, Polvani LM (2001) The weak temperature gradient approximation and balanced tropical moisture waves. J Atmos Sci 58:3650-3665. https://doi.org/10.1175/15200469(2001)058\%3c3650:TWTGAA\%3e2.0.CO;2

$\mathrm{Su}$ H, Neelin JD, Meyerson JE (2003) Sensitivity of tropical tropospheric temperature to sea surface temperature forcing. J Clim 16:12831301. https://doi.org/10.1175/1520-0442-16.9.1283

Su H, Neelin JD, Meyerson JE (2005) Mechanisms for lagged atmospheric response to ENSO SST forcing. J Clim 18:4195-4215. https ://doi.org/10.1175/JCLI3514.1

Talley LD, Pickard GL, Emery WJ, Swift JH (2011) Mass, salt, and heat budgets and wind forcing. In: Talley LD, Pickard GL, Emery WJ, Swift JH (eds) Descriptive physical oceanography, 6th edn. Academic Press, Boston, pp 111-145

Tao W, Huang G, Hu K et al (2016) A study of biases in simulation of the Indian Ocean basin mode and its capacitor effect in CMIP3/ CMIP5 models. Clim Dyn 46:205-226. https://doi.org/10.1007/ s00382-015-2579-0

Timmermann A, An S-I, Kug J-S et al (2018) El Niño-Southern Oscillation complexity. Nature 559:535-545. https://doi.org/10.1038/s4158 6-018-0252-6

Trenberth KE, Branstator GW, Karoly D et al (1998) Progress during TOGA in understanding and modeling global teleconnections associated with tropical sea surface temperatures. J Geophys Res 103:14291-14324. https://doi.org/10.1029/97JC01444

Wang C (2002) Atmospheric circulation cells associated with the El Niño-Southern Oscillation. J Clim 15:399-419. https://doi. org/10.1175/1520-0442(2002)015\%3c0399:ACCAWT\%3e2.0.CO;2

Wang C, Xie S-P, Carton JA (2004) A global survey of ocean-atmosphere interaction and climate variability. In: Wang C, Xie S-P, Carton JA (eds) Earth's climate: the ocean-atmosphere interaction. American Geophysical Union, Washington, DC, pp 1-19

Wang L, Yu J-Y, Paek H (2017) Enhanced biennial variability in the Pacific due to Atlantic capacitor effect. Nat Commun 8:14887. https ://doi.org/10.1038/ncomms 14887

Wu B, Li T, Zhou T (2010) Relative contributions of the Indian Ocean and local SST anomalies to the maintenance of the western North Pacific anomalous anticyclone during the El Niño decaying summer. J Clim 23:2974-2986. https://doi.org/10.1175/2010JCLI3300.1

Wu B, Zhou T, Li T (2009) Seasonally evolving dominant interannual variability modes of East Asian climate. J Clim 22:2992-3005. https ://doi.org/10.1175/2008JCLI2710.1

Wu R, Yeh S-W (2010) A further study of the tropical Indian Ocean asymmetric mode in boreal spring. J Geophys Res 115:D08101. https://doi.org/10.1029/2009JD012999

Xie S-P, Hu K, Hafner J et al (2009) Indian Ocean capacitor effect on Indo-western Pacific climate during the summer following El Niño. J Clim 22:730-747. https://doi.org/10.1175/2008JCLI2544.1

Xie S-P, Kosaka Y, Du Y et al (2016) Indo-western Pacific ocean capacitor and coherent climate anomalies in post-ENSO summer: a review. Adv Atmos Sci 33:411-432. https://doi.org/10.1007/s0037 6-015-5192-6

Xie S-P, Philander SGH (1994) A coupled ocean-atmosphere model of relevance to the ITCZ in the eastern Pacific. Tellus Dyn Meteorol Oceanogr 46:340-350. https://doi.org/10.3402/tellusa.v46i4.15484

Yu J-Y, Mechoso CR, McWilliams JC, Arakawa A (2002) Impacts of the Indian Ocean on the ENSO cycle. Geophys Res Lett 29:46-1-4. https://doi.org/10.1029/2001GL014098

Yu J-Y, Wang X, Yang S et al (2017) The changing El Niño-Southern Oscillation and associated climate extremes. In: Wang S-YS, Yoon J-H, Funk CC, Gillies RR (eds) Climate extremes: patterns and mechanisms. American Geophysical Union, Washington, DC, pp $1-38$ 
Yu J-Y, Zou Y, Kim ST, Lee T (2012) The changing impact of El Niño on US winter temperatures. Geophys Res Lett 39:L15702. https:// doi.org/10.1029/2012GL052483

Zhang Y, Xu H, Qiao F, Dong C (2018) Seasonal variation of the global mixed layer depth: Comparison between Argo data and FIOESM. Front Earth Sci 12:24-36. https://doi.org/10.1007/s1170 7-017-0631-6

Zienkiewicz OC, Zhu JZ (1992) The superconvergent patch recovery and a posteriori error estimates. Part 1: the recovery technique.
Int J Numer Methods Eng 33:1331-1364. https://doi.org/10.1002/ nme. 1620330702

Publisher's Note Springer Nature remains neutral with regard to jurisdictional claims in published maps and institutional affiliations. 